\title{
MIDAS
}

Museus e estudos interdisciplinares

$10 \mid 2019$

Varia

\section{Maria da Luz Sampaio - Da Fábrica ao Museu. Identificação, Patrimonialização e Difusão da Cultura Técnico-industrial}

\section{Ana Paula Pires}

\section{(2) OpenEdition}

\section{Journals}

Edição electrónica

URL: http://journals.openedition.org/midas/1537

DOI: $10.4000 /$ midas. 1537

ISSN: 2182-9543

Editora:

Alice Semedo, Paulo Simões Rodrigues, Pedro Casaleiro, Raquel Henriques da Silva, Ana Carvalho

\section{Refêrencia eletrónica}

Ana Paula Pires, « Maria da Luz Sampaio - Da Fábrica ao Museu. Identificação, Patrimonialização e Difusão da Cultura Técnico-industrial », MIDAS [Online], 10 | 2019, posto online no dia 31 maio 2019, consultado no dia 24 setembro 2020. URL : http://journals.openedition.org/midas/1537 ; DOl : https:// doi.org/10.4000/midas. 1537

Este documento foi criado de forma automática no dia 24 setembro 2020.

\section{(c) (1) (-)}

Midas is licensed under a Creative Commons Attribution-NonCommercial-ShareAlike 3.0 International License 


\title{
Maria da Luz Sampaio - Da Fábrica ao Museu. Identificação, Patrimonialização e Difusão da Cultura Técnico-industrial
}

\author{
Ana Paula Pires
}

\section{REFERÊNCIA}

Sampaio, Maria da Luz. 2017. Da Fábrica ao Museu. Identificação, Patrimonialização e Difusão da Cultura Técnico-industrial. Vol. 9. Coleção Estudos de Museus. Casal de Cambra: Caleidoscópio e Direção-Geral do Património Cultural. 373 páginas, ISBN:

978-989-658-490-0.

1 A 5 de Agosto de 1963, após oito anos de negociações difíceis o presidente norteamericano John F. Kennedy assinou com representantes do Reino Unido e da Rússia o tratado que limitava a realização de experiências nucleares. ${ }^{1}$ A caneta com que Kennedy assinou o documento encontra-se emoldurada numa das paredes do edifício "Encina" no campus da Universidade de Stanford, em Palo Alto, na Califórnia. Fazer história implica conhecer os traços distintivos de cada época, compreender conjunturas, enquadrar realidades nacionais e transnacionais, bem como as mudanças e as transformações, do mundo globalizado, que lhes deram origem; mesas, cadeiras, garrafas, máquinas a vapor, relógios ou a caneta usada por Kennedy ajudam-nos a escrever essa história, estabelecendo ligações vivas entre o passado e o presente (cf. Ulrich et al. 2015).

2 Porque é que há objectos dos quais não nos separamos? O que é que estes objectos dizem de nós? Como é que esta realidade tangível nos ajuda a compreender o mundo? De que modo é que os objectos nos ajudam a compreender o passado? o livro de Maria da Luz Sampaio permite-nos analisar a industrialização, na cidade do Porto, tendo como principal fonte um objecto: o motor eléctrico ASEA. Apesar da contemporaneidade ser uma experiência transversal ao mundo ocidental, esta não deve 
ser lida como uma realidade homogénea, mas antes como um período heterogéneo marcado por ritmos e temporalidades distintas. O motor eléctrico ASEA ajuda-nos a entender e a enquadrar essas cadências que nos remetem para a dimensão social do passado industrial, sublinhando a importância da realidade tangível num mundo actual, cada vez mais marcado pelo digital.

3 Maria da Luz Sampaio é doutorada em História e Filosofia da Ciência, especialidade Museologia, pela Universidade de Évora. O seu percurso profissional é o objecto central do estudo Da Fábrica ao Museu. Identificação, Patrimonialização e Difusão da Cultura Técnicoindustrial. Sampaio desempenhou funções de directora do Museu da Indústria do Porto entre 2000 e 2011, projecto em que esteve envolvida desde 1992, quando teve início a inventariação do património industrial da cidade. A sua dissertação de doutoramento, defendida em 2015, e que agora se publica, reflecte um percurso profissional dinâmico e combina duas dimensões, nem sempre fáceis de conjugar: percurso académico e experiência de vida.

40 trabalho encontra-se dividido em quatro capítulos: (i) «O Património Industrial na Atualidade: Emergência e Desafios»; (ii) «Os Objetos-artefactos Técnico-industriais: Identificação e Métodos de Análise»; (iii) «Representações do Património Industrial do Porto: Coleção e Museu»; e (iv) «O Artefacto 'Motor Eléctrico': Apresentação e Análise de um Estudo de Caso», este último traçando a biografia do objecto escolhido como elemento central da dissertação.

5 Segundo Sampaio os objectos «conjugam-se entre si, criando diagramas de produção, linhas de fabrico e seções específicas que nos transportam para o saber-fazer, a mecanização ou a automação dos processos tecnológicos e, sobretudo, para a aplicação prática de princípios técnico-científicos» (p. 7). São estes objectos que nos vão ajudar a construir as "paisagens da produção", conceito inovador que a autora introduz ${ }^{2}$, assim como a distinguir entre património industrial móvel e imóvel e a identificar as medidas necessárias para a respectiva salvaguarda:

Se o edificado está mais facilmente sujeito à usura da especulação imobiliária, os "objectos móveis", os "valores técnicos" invocados nas cartas, Convenções Internacionais ou na Lei de Bases do Património, são aqueles que estão mais sujeitos ao vandalismo, à venda ou até à dispersão. Reverter esta situação implica um conhecimento prévio das realidades sociais e económicas quer da população, quer do tecido empresarial, uma actuação dos técnicos e especialistas do património no território, junto dos proprietários, e o entendimento por parte do Estado de que o património móvel é um recurso [...]. (p. 55)

O trabalho, que se situa cronologicamente entre 1920 e 1970, remete-nos, ainda, imediatamente para o papel dos engenheiros ao longo da História e para o facto de se terem constituído como um dos protagonistas das grandes alterações económicas e sociais que ocorreram na Europa e na América do Norte a partir dos finais do século XVIII; a partir da chamada I Revolução Industrial o seu prestígio não parou de crescer, a era da produção e das comunicações que então se abriu tornou-os imprescindíveis: os engenheiros transformaram-se num dos principais agentes da produção industrial e do progresso, realidade a que Portugal não foi excepção (Rollo e Pires 2012). E neste sentido vale a pena entender em que medida as sucessivas conjunturas históricas que marcaram a contemporaneidade portuguesa, e que a autora identifica, foram determinadas pelo percurso da engenharia em Portugal como sublinhou Araújo Correia a «(...) engenharia é a profissão da criação e construção, é a profissão que estimula e avigora o espírito humano» (Correia 1927a, 55; Correia 1927b, 1-3). 
7 Vale a pena ter presente ainda a disputa e a conquista, do poder, da ciência, da técnica, de um mundo empresarial de feição mais moderna que vai emergindo entre o pós I Guerra Mundial e o início da década de 1970, realidade essa condicionada pelos desígnios da mutação tecnológica que entra em ritmo surpreendentemente acelerado, a que se irá associar, como a autora indica, o desenvolvimento do ensino técnico e superior e a lenta e gradual aproximação dos poderes públicos da iniciativa privada.

o livro de Maria da Luz Sampaio permite-nos reflectir em torno de três grandes questões: (i) até que ponto o passado industrial é importante; (ii) através de que meios desenvolvemos a nossa percepção do passado; (iii) e de que forma se tem construído a memória histórica.

9 O estudo leva-nos também a considerar a evolução da "cultura popular" e o modo como a contemporaneidade com ela se tem integrado e/ou interagido, nomeadamente, no âmbito do desenvolvimento, crescente, de fenómenos, cada vez mais significativos, que podemos apelidar de "consumismo-patrimonial", e que, acima de tudo, servem para demonstrar que o monopólio do conhecimento histórico há muito deixou de pertencer à academia, como Maria da Luz Sampaio muito bem sublinha ao demonstrar a importância de «[...] antigos operários, fundadores e proprietários, técnicos e engenheiros [...] os primeiros agentes do processo de patrimonialização destes objectos» (p. 13).

10 A autora recua a 1807 ano em que tiveram lugar as primeiras iniciativas tendo em vista a criação de um museu da indústria em Portugal, reflectindo também em torno do desenvolvimento de projectos de inventariação e de musealização, a partir do início da década de 1980, para analisar o modo como este património tecnológico e industrial se relaciona com a evolução da ciência, da tecnologia e da indústria (ver também Alfrey e Putman 1992). Importante ainda é a forma como o Museu da Indústria se foi assumindo como um agente de preservação da cultura industrial da cidade do Porto, sendo a sua colecção representativa das principais marcas de equipamentos industriais europeus B.B.C, Siemens, AEG, Foster, MIAG, ARENCO, Klimsh - bem como de marcas nacionais (muitas portuenses) - EFACEC, CIF, Electro-Cerâmica, Fundição de Massarelos, MECAMPE, EFANOR, FACAR, Produtos Coração e Companhia Portuguesa do Cobre (p. 329).

11 Este livro que procura o equilíbrio que enforma o conhecimento histórico: mudança e continuidade, demonstra uma grande preocupação com a "educação histórica" e com a transmissão da memória e do conhecimento de geração para geração. A autora busca, deste modo, a formação de um saber construtivo, capaz de transpor os muros da Universidade, propagando-se à sociedade no seu todo, numa clara preocupação de fazer dotar a sociedade de instrumentos que possibilitem entender o passado e a preservação dos objectos que contam a sua história, num mundo cada vez mais obcecado com o virtual.

12 Maria da Luz Sampaio questiona categorias e divisões, em grande parte ainda presentes nas colecções dos museus de ciência, para concluir que a história não é feita apenas de documentos escritos, levando-nos de imediato a repensar a realidade tangível que nos rodeia. 


\section{BIBLIOGRAFIA}

Alfrey, Judith, e Putman, Tim. 1992. The Industrial Heritage. Managing Resources and Uses. London: Routledge.

Boda, Chad S. 2017. "The Politics of Landscape Production in the History of Development along Florida's Atlantic Coast." Landscape Research 42 (4): 361-374.

Correia, José de Araújo. 1927a. “O Ensino Superior Técnico nos Países Anglo-saxónicos - e sua Relação com a Moderna Função Social do Engenheiro.” Revista da Associação dos Engenheiros Civis Portugueses 640 (Março-Julho): 55.

Correia, José de Araújo. 1927b. “A Função Social do Engenheiro.” Técnica 6 (15 de Janeiro): 1-3.

Rollo, Maria Fernanda, e Ana Paula Pires. 2012. Ordem dos Engenheiros - 75 Anos de História. Inovação e Desenvolvimento em Portugal: O Lugar dos Engenheiros. Lisboa: Ingenium Edições Lda.

Ulrich, Laurel Thatcher, Ivan Gaskell, Sara Schechner, Sarah Anne Carter, e Samantha van Gerbig, eds. 2015. Tangible Things: Making History Through Objects. Oxford: Oxford University Press.

\section{NOTAS}

1. A autora escreve de acordo com a antiga ortografia.

2. Sobre as paisagens da produção ver o recente artigo de Boda (2017).

\section{AUTORES}

\section{ANA PAULA PIRES}

Instituto de História Contemporânea, Faculdade de Ciências Sociais e Humanas da Universidade Nova de Lisboa, Portugal, asoarespires@gmail.com 